\title{
Association of seed mycoflora with peas Pisum sativa L. seeds
}

\author{
Sidra Qaim khani ${ }^{1}$, M. Ibrahim Khaskheli ${ }^{1,4 *}$, M. Mithal Jiskani², Imtiaz A. \\ Nizamani $^{1}$, Allah Jurio Khaskheli ${ }^{3}$, Xiaoli Chang ${ }^{4}$, and Aisha Anum ${ }^{1}$
}

\author{
${ }^{1}$ Department of Plant Protection, Sindh Agriculture University, Tandojam-70060, Pakistan \\ ${ }^{2}$ Department of Plant Pathology Sindh Agriculture University, Tandojam-70060, Pakistan \\ ${ }^{3}$ Department Biotechnology, Sindh Agriculture University, Tandojam-70060, Pakistan \\ ${ }^{4}$ Department of Plant Protection, College of Agronomy, Sichuan Agricultural University, Chengdu, 611130, P.R. \\ China \\ *Address correspondance
}

\begin{abstract}
Seed is a vital source for producing optimum yield. Seed-borne pathogens may cause losses by reducing seed germination, developing seed-borne diseases and mortality of seedlings in nursery beds. However, knowledge of the about the biology and extent of seed-borne pathogens and thereafter practices for their management can help to reduce seed and seedling losses. Thus, present studies were conducted to find out the association of seed associated mycoflora with major vegetable peas in the laboratories of Department of Plant Protection, Sindh Agriculture University and Federal Seed Certification and Registration Department, Karachi, Sindh, Pakistan from February to October 2017. Total of 10 different fungal species belonging to different genera was isolated from peas seeds through blotter paper and agar plate methods. Significantly highest frequency percent for Alternariaalternata (50\%), Aspergillus fumigates (48.33\%), A. niger (36.67\%), A. flavus (23.33\%), C. lunata (17.5\%) and F. oxysporum (17.5\%). However, the lowest frequency was recorded for $T$. viride (4.17\%), R. stolonifer (5\%), Penicillium sp. (5.83\%) and Stemphylium (11.67\%) through the agar plate method. A similar trend of frequency was noticed for blotter paper in all recorded fungi; however, the extent was lower compared to the agar plate method. The results of the present studies provide the baseline information about seed mycoflora for further studies and management of seed-borne diseases associated with peas seeds.
\end{abstract}

Keywords-Pisum sativa, Seed Mycoflora, Isolation methods.

\section{INTRODUCTION}

Pea, Pisum sativa $\mathrm{L}$ is the most important vegetable and is cultivated throughout the world for consumption of human being and animals. It is one of the richest, cheapest and readily available sources of minerals, vitamins, protein, and carbohydrates. It is a valuable food product due to the rich source of nutrients that capable of meeting the dietary needs of approximately eight hundreds to nine hundred million undernourished peoples throughout the world [1].

However, the yield is influenced by the number of foliar and soil-borne diseases. Moreover, the pea is the most sensitive to damping off and root and foot rots caused by seed and soil-borne fungal pathogens [2]. The infestation in the seed may results occurrence of severe diseases in subsequent crop [3]. Varying degrees of discoloration and shriveling can be seen in infected seeds; however, sometimes other even infected seeds remain symptomless $[4, \mathbf{5}, \mathbf{6}]$.

In pea, Ascochyta blight disease is caused by three seedborne fungal species such as Ascochytapisi, Phomapinodella, and Mycosphaerellapinodes. These species can also survive on plant residues in soil. Generally, such fungi occur individually or some time in combination and then referred to as the Ascochyta complex $[7,8]$. Seed-borne infestation by $P$. pinodella and $M$. pinodes generally causes more severe and widespread seedling diseases compared to an infestation of $A$. pisi[3]. In addition to Ascochyta complex, several other seed-borne pathogens such as Alternariaalternata, A. tenuissima, Penicillium spp., Fusarium spp. and other fungi that may also cause root rots and reduce the germinating power, deteriorate seedlings', affect health and growth of pea $[\mathbf{9 , 1 0}]$.

It is obvious that most of the important seed borne diseases caused by pathogens are disseminated by seeds; thus, it is known as passive carriers, often cause significant losses in yield. So for sustainable production and quality yield, use of disease-free and healthy seeds have been recognized best approach. Therefore, knowledge about seed health and quality, proper seed 
testing is essential to get tasks. Thus, the present investigation was conducted to analyze the seed as sociated mycoflora of peas vegetable.

\section{MATERIAL AND METHOD}

\subsection{Study locations}

The present study was conducted in the laboratories of the Department of Plant Protection, Sindh Agriculture University and Federal Seed Certification and Registration Department, Karachi, Sindh, Pakistan.

\subsection{Collection of Seed Samples}

Seed samples of peas kindly provided by Federal Seed Certification and Regis tration Department, Karachi, Sindh, Pakistan for isolation and identification of seed mycoflora and seed health analysis. Seed samples assessed at the laboratory of Federal Seed Certification and Registration Department and brought to the laboratory of Department of Plant Protection, Sindh Agriculture University, Tandojam, Pakistan for further studies.

\subsection{Isolation and identification of seed mycoflora}

Seed samples of peas were randomly collected for isolation purpose. Samples were placed in paper bags and brought for isolation and identification of seed mycoflora in the laboratories of Federal Seed Certification and Registration Department and Department of Plant Protection, Sindh Agriculture University, Tandojam.

\subsubsection{Isolation of Seed mycoflora}

Isolation of seed-borne mycoflora associated with peas was conducted by using isolation techniques described by the International Rules for Seed Testing Association (ISTA, 2015) as under:

\subsubsection{Standard blotter method}

Seed samples of peas were tested by standard blotter method for the isolation of associated mycoflora. Three layers of blotter papers circular in shape and 150 and 90 $\mathrm{mm}$ diameter according to the size of Petri dishes were cut with the help a scis sor. The blotters were dipped and moistened with sterilized distilled water and excess water was removed from the Petri dishes. The mo istened blotter papers were transferred to sterilized Petri dish with the help of sterilized forceps. Randomly collected seed samples were thoroughly washed with tap water and then dried. These seeds were surface sterilized in 0.1 percent mercuric chloride solution $(\mathrm{HgCl} 2)$ for 30 seconds followed by three washing with sterilized distilled water in beakers under aseptic conditions using laminar air flow. All seeds were then completely dried by placing on sterilized blotting paper. A total of 12 seeds were placed in such a manner that 11 were in an outer circle and one in the center. The seeded Petri dishes were incubated in the chamber. Seeds were examined on $3^{\text {rd }}$ days, $5^{\text {th }}$ days and $07^{\text {th }}$ days after incubation (DAI).

2.3.1.2 The standard agar plate method

In the standard agar plate method, seeds were surface sterilized as described earlier. Five seeds were transferred aseptically to the Petri plates containing sterile potato dextrose agar (PDA) medium amended with an antibacterial agent and filled up to quarter strength in a manner that 4 seeds were kept at the outer circle and 01 seed at the center of Petri dish. The inoculated plates were incubated at $25 \pm 20^{\circ} \mathrm{C}$.

All the plates were monitored regularly and growing colonies were subjected to different laboratory codes for frequency percentage and further analysis.The culture, thus, obtained was subjected to purification. A single spore culture technique was used to purify the isolates. Sub-culturing of isolates were made time to time to maintain the fresh culture for further analysis until the end of experiments.

\subsubsection{Identification of pathogens}

Temporary slides of fungal isolates from pure cultures were made and observed under a light microscope. Morphological and cultural characters of isolated fungi were recorded and compared with standard keys for establishing their identity (Barnett and Hunter 1972; Booth and Sutton 1984; Nelson et al. 1983). In addition, internet databases were also used to compare the morphological characteristics of is olates.

\subsection{Determination of extent of seed mycoflora}

Determination of extent of seed associated mycoflora with major vegetable crops viz; peas, bottle gourd, cucumber, and to mato were evaluated from both methods; standard blotter paper and agar plate method. The extent of seed associated mycoflora from each vegetable was calculated by using the following formula:

$$
\begin{aligned}
& \text { Frequency (\%) } \\
& =\frac{\text { Number of Pieces colonized }}{\text { Total Number of Pieces studied }} \text { X100 }
\end{aligned}
$$

\subsection{Statistical analysis}

The data obtained in present were statistically analyzed by using the standard procedures for analysis of variance, ANOVA (linear model), and mean separation (least significant difference, LSD) of all parameters by using the computer software Statistix 8.1 [15].All differences described in the text were significant at the $5 \%$ level of probability.

\section{RESULTS}


The results so far achieved are summarized here and hope that will be helpful for pre-sowing seed treatments and sustainable management of seed associated mycoflora.

\subsection{Isolation and identification of seed mycoflora}

The association of seed associated fungi isolated through blotter paper and the agar plate method showed great variability. It was observed that higher numbers of fungal isolates were preferably grown on agar plates compared to blotter papers. A total of 09 fungi viz; Alternariaralternata, Aspergillusflavus, A. fumigates, A. niger, Curvularialunata, F. oxysporum, Penicillium, Rhizopusstoloniferand Stemphylium. However, Trichodermaviride was the only fungus isolated through the agar plate method Fig. 1.

\subsection{The extent of seed ass ociated mycoflora}

The frequency percent of different fungi showed significant variation $(P<0.05=0.0000$ and0.0000) among different isolates recorded for both blotter paper and agar plate method, respectively. However, no significant difference was found observed among the different seed samples of two years $(P<0.05=0.8918$ and 0.5087$)$ for both blotter paper and agar plate method, respectively (Table 1).

The frequency percent of seed mycoflora with peas seed showed significantly highest percent for A. alternata (28.33 and $36.66 \%$ ) followed by A. niger (25 and $31.66 \%$ ), C. lunata (20 and 10\%), R. stolonifer (18.33 and $13.33 \%), F$. oxysporum (15 and $11.66 \%$ ) and A. fumigates (15 and 16.667\%) from the samples of 2016 and 2017, respectively (Figure 2). However, the frequency percent of A. fumigates from the seeds of 2017 was a bit higher $(16.667 \%)$ compared to $R$. stolonifer $(13.33 \%), F$. oxysporum (11.66\%) and C. lunata (10\%). Whereas significantly lowest frequency percent was recorded for Stemphylium sp. (0 and 3.333) followed by Penicillium (8.33 and 5\%), A. flavus (11.67 and 16.67\%) from the seeds of 2016 and 2017, respectively (Fig. 2) through blotter paper.

The frequency percent of seed mycoflora isolated through the agar plate method from the peas seed samples of 2016 and 2017 showed significantly highest percent for A. fumigates (60 and $36.67 \%$ ) followed by A. alternata (45 and 55\%), A. niger (33.33 and 40\%), C. lunata (25 and $10 \%$ ) and $F$. oxysporum (20 and $15 \%$ ), respectively (Figure 3). However, the frequency percent of $A$. alternata $(55 \%)$ was higher than A. fumigates $(36.67 \%)$. Significantly lowest frequency percent was recorded for $R$. stolonifer (5 and 5\%) followed by Penicillium sp. (6.67and 5\%), T. viride (8.33 and 0), Stemphyliumsp. (10 and $13.33 \%$ ) and A. flavus (16.67 and 30\%) from the seeds of 2016 and 2017, respectively. However, $T$. viridewas not recorded from the seed of 2017 through agar plate method as well through blotter paper methods during both years of seed (Fig. 3).

On an overall basis, the mean of two years for the frequency of fungi showed significant $(P<0.05=0.0000$ and 0.0001) difference among the different isolates and methods, respectively. However, no significant difference $(P<0.05=0.7690)$ was found observed among the different seed samples of two years for overall frequency percent (Table 1). Significantly, highest frequency percent was recorded for A. alternata (32.5\%) followed by $A$. niger $(28.33 \%), \quad A$. fumigates $(15.83 \%), \quad R$. stolonifer $(15.83 \%)$ and $C$. lunata $(15 \%)$ isolated through blotter paper method from peas seed. However, Stemphylium sp. (1.67\%) followed by Penicillium sp. (6.67\%) and F. oxysporum (13.33\%) and A. flavus $(14.17 \%)$ were recorded with the lowest frequency in blotter paper method (Table 2). The frequency in the agar plate method of peas seed showed little variation compared to blotter paper method. The highest frequency was recorded for A. alternata (50\%), A. fumigates (48.33\%), A. niger (36.67\%), A. flavus (23.33\%), C. lunata $(17.5 \%)$ and $F$. oxysporum $(17.5 \%)$. However, the lowest frequency was recorded for $T$. viride $(4.17 \%), R$. stolonifer (5\%), Penicillium sp. (5.83\%) and Stemphylium $(11.67 \%)$ through agar plate method (Table 2).

Moreover, when the interaction was assessed for the frequency percent of both fungi and methods revealed a significant difference $(P<0.05=0.0005)$. Majority of the fungal isolates prefer to grow on agar plates instead of blotter paper; thus, the significantly maximum frequency of a majority of fungi was recorded from agar plate methods except for two fungi, $R$. stolonifer, and Penicillium sp. that produce higher frequency on blotter paper. The interaction of fungi and years revealed no significant difference $(P<0.05=0.0935)$ among the different isolates for 2016 and 2017 seeds of peas (Table 2).

\section{DISCUSSION}

Seeds play an important role in producing optimum yield through healthy crop production. Healthy seeds, particularly pathogen-free seeds, are necessary for the maintenance of optimum plant populations and production. Approximately $16 \%$ of crop losses occur due to plant diseases annually, however, out of which about $10 \%$ loss takes place due to seed-borne diseases has been reported by Fakir (1983). Seed-borne pathogens may cause losses by reducing seed germination, developing damping-off diseases, and mortality of older seedlings in 
nursery beds. Sometimes seed fails to germinate (Mahmoud et al. 2013; Haikal, 2008) or losses have occurred in containers during transportation (Campbell and Landis, 1990). However, knowledge of the about the biology and extent of seed-borne pathogens and thereafter practices for their management can help to reduce seed and seedling losses. Thus, present studies were conducted to find out the association of seed associated mycoflora with major vegetable crops in the laboratories of Department of Plant Protection, Sindh Agriculture University and Federal Seed Certification and Registration Department, Karachi, Sindh, Pakistan from February to October 2017.

The association of seed associated mycoflora revealed the diversity of fungal species are associated with seeds that may cause ultimately severe losses to peas vegetable. A total of 10 fungal species were isolated from the seeds of peas. With reference to seed associated fungi with different vegetable seeds, several studies have been conducted; however, the number and species reported mycoflora were different compared to present studies that might be due to the genetic potential of seeds and climatic conditions of the areas.Sheela (2015) determined the association of 15 genera and 29 species of fungi from the seeds of Pigeon pea. Avinash and Rai (3013) also isolated seed-borne fungi of the Cucurbitaceae family using the standard blotter method and deep-freeze method. They is olated and identified about 26 genera and 39 species of fungal colonies. The association of seed associated fungi isolated through blotter paper and agar plate method in the present study showed great variability. It was observed that a higher number of fungal isolates was preferably grown on agar plates compared to blotter papers. Our studies are inconsistent with Sheela (2015), she reported both blotter method and agar plate method as the most suitable technique for the detection of fungi. Though both methods in current remained conducive, however, higher frequency of fungi was recorded with the agar plate method. A total of 10 fungi were found associated with peas seeds, including 09 fungi viz; Alternariaralternata, Aspergillusflavus, A. fumigates, A. niger, Curvularialunata, F. oxysporum, Penicillium, Rhizopusstolonifer and Stemphylium were isolated through blotter paper methods. However, one additional fungus, Trichodermaviride was isolated through the agar plate method in addition to the above nine fungi. Avinash and Rai (3013) isolated seed-borne fungi of the Cucurbitaceae family using the standard blotter method and deep-freeze method. They isolated 08 fungi from bottle and ridge gourd such as Fusariumverticillioides, $F$. oxysporum, Alternariacucumerina, A. alternata, Chaetomiumglobosum, C. indicum, C. crispatum and $C$. funicola. F. verticillioides and $F$. oxysporum. Whereas from pumpkin seeds only $F$. oxysporum and Cladosporiumcucumerinum; and Alternariacucumerina and Alternariaalternata were isolated from bitter gourd seeds.

The great variability was found observed for the extent of associated fungi isolated through blotter paper and agar plate methods from seed samples of years, 2016 and 2017. The extent of seed associated fungi revealed significant variation $(P<0.05=0.0000$ and 0.0000$)$ among different isolates recorded for both blotter paper and agar plate method, respectively. However, no significant difference was found observed among the different seed samples of two years $(P<0.05=0.8918$ and 0.5087$)$ for both blotter paper and agar plate method, respectively. The frequency percent of seed mycoflora with peas seed showed significantly highest percent for A. alternata (28.33 and $36.66 \%$ ) followed by A. niger (25 and $31.66 \%)$, C. lunata (20 and 10\%), R. stolonifer (18.33 and $13.33 \%), F$. oxysporum (15 and $11.66 \%$ ) and A. fumigates (15 and 16.667\%) from the samples of 2016 and 2017, respectively. Whereas significantly lowest frequency percent was recorded for Stemphylium sp. (0 and 3.333) followed by Penicillium (8.33 and 5\%), A. flavus (11.67 and $16.67 \%$ ) from the seeds of 2016 and 2017, respectively, through blotter paper. The frequency percent through agar plate was almost similar to blotter paper method, only litter variation was found observed in the extent and number of isolates. On an overall basis, the mean of two years for the frequency of fungi showed a significant difference among the different isolates and methods, respectively. However, no significant difference was found observed among the different seed samples of two years for overall frequency percent. Significantly, highest frequency percent was recorded for A. alternata (32.5\%) followed by A. niger(28.33\%), A. fumigates (15.83\%), R. stolonifer(15.83\%) and C. lunata (15\%) isolated through blotter paper method from peas seed. However, Stemphylium sp. (1.67\%) followed by Penicillium sp. (6.67\%) and F. oxysporum (13.33\%) and A. flavus (14.17\%) were recorded with the lowest frequency in blotter paper method. The frequency in the agar plate method of peas seed showed little variation compared to blotter paper method. The highest frequency was recorded for A. alternata (50\%), A. fumigates (48.33\%), A. niger (36.67\%), A. flavus (23.33\%), C. lunata $(17.5 \%)$ and $F$. oxysporum $(17.5 \%)$. However, the lowest frequency was recorded for $T$. viride $(4.17 \%), R$. stolonifer (5\%), Penicillium sp. (5.83\%) and Stemphylium $(11.67 \%)$ through the agar plate method. Moreover, when the interaction was assessed for the frequency percent of both fungi and methods revealed a significant difference 
$(P<0.05=0.0005)$. Majority of the fungal isolates prefer to grow on agar plates instead of blotter paper; thus, the significantly maximum frequency of a majority of fungi was recorded from agar plate methods. The interaction of fungi and years revealed no significant difference $(P<0.05$ $=0.0935)$ among the different isolates for 2016 and 2017 seeds of peas. In the literature, very few studies are available with regards to seed associated mycoflora with peas vegetable. In one study, Wilmanet al. (2014) identified the pathogens present in the seeds of the tested cultivars viz; Alternaria spp. as predominant followed by Fusarium spp., Stemphylium spp., Ulocladium spp., Botrytis cinerea Pers., Epicoccumnigrum Link., and Phomapinodella. Ozgonen and Gulcu (2011) also determined mycoflora of pea seeds and found some most common fungi viz; Fusarium spp., Alternaria spp., Macrophominaphaseolina, Phytophthoramegasperma, Rhizoctoniasolani and Sclerotiumrolfsii from peas seed. Marcinkowska (2010) conducted a study during 2004 and 2006 in Pisumsativum seed; maximum fungal species (27) were noticed in 2004, while the minimum (16) during 2006. Significantly, the highest frequency was recorded for A. alternata compared to other fungal species viz; Fusariumsp., Penicillium,Phoma, Stemphylium Mycosphaerella, and Ascochyta. Our studies are also in agreement with Marcinkowska (2010) with regard to the association of seed mycoflora in older seeds was higher compared to newer seeds. Moreover, in the current study A. alternata was also isolated with the highest frequency.

\section{CONCLUSION}

It is obvious that seed-borne pathogens can cause severe losses to the crop by reducing seed germination, developing seed-borne diseases and mortality of seedlings in nursery beds. A total of 10 different fungal species belonging to different genera were isolated from peas seeds through blotter paper and agar plate methods revealed the association fungal pathogen with peas seeds. The results of present studies provide the baseline information about seed mycoflora for further studies and manage ment of seed-borne diseases associated with Peas seeds in Sindh Province of Pakistan

\section{ACKNOWLEDGEMENTS}

We are grateful to Sindh Agriculture University, Tandojam, Pakistan to facilitate us to perform the experiments.

\section{REFERENCES}

[1] FAO(2011) Food and Agriculture Organization Statisitics. Food Security Data and Definitions
2005-2007. Food Deprivation. Number of Undernourished Persons.

http://www.fao.org/economic/ess/ess-fs/fs-data/essfadata/en/.

[2] Bowen J K (1992). The identity and pathogenicity of fungi of the 'Ascochyta complex' on Pisum seeds: Ph.D thesis; University of East Anglia-Norwich,UK.

[3] Setti B, Bencheikh $M$ and Henni JC (2009).Comparative aggressiveness of Mycosphaerellapinodes on peas from different regions in western Algeria. Phytopathologia Mediterranea, 48: 195-204.

[4] Marcinkowska J, Boros $\mathbf{L}$ and Wawer $A$. (2009).The response of pea (Pisumsativum L.) cultivars and lines to seed infestation by Ascochyta blight fungi. Plant Breeding and Science, 59: 75-86.

[5] Boros L and Marcinkowska J.(2010). Assessment of selected pea genotypes reaction to Ascochyta blight under conditions and the impact of disease severity on yield components. Journal of Agriculture Science, 2(3): 84-91.

[6] Wallen VR (1965). Field evaluation and importance of the Ascochyta complex on peas. Canadian Journal of Plant Science, 45: 27-33.

[7] Onfroy C, Tivol B, Corbiere $R$ and Bouznad $Z$ (1999). Cultural, molecular and pathogenic variability of Mycosphaerellapinodes and Phomamedicaginis var. pinodella isolate from dried pea (Pisumsativum) in France. Plant Pathology, 48: 218-229.

[8] Prokinova $E$ and Markova $Z$ (1997). Effect of Fusarium spp. and Alternariaspp. on pea sprouting. Rostlinna Vyroba, 43 (11): 517-523.

[9] Marcinkowska J (2008). Fungi occurrence on seeds of field pea. Acta Mycologica, 43(1): 77-89.

[10] IS TA (2015). International Rules for Seed Testing 2015. International Seed Testing Association, Bassersdorf, Switzerland.

[11] Barnett HL and Hunter B (1972). Illustrated genra of imperfect fungi. Burgress publishing company Minneapolis.

[12] Booth C and Sutton BC (1984). Fusariumpallidoroseum, the correct name for $F$. semitectum. Transactions of British Mycological Society, 23 (4) : 702-704.

[13] Nelson PE, Toussoun TA and Marasas WFO (1983). Fusariumspecies. An illustrated manual of identification. The State Univ. Press, University Park, Pennslyvania.

[14] Analytical Software (2005). Statistix 8.1, Tallahassee, FL. 
[15] Fakir GA (1983).Teaching, research and training activities on seed pathology in Bangladesh. Seed Sci. Technol, 11:1345-1352

[16] Mahmoud S YM, Hosseny MH, EL-Shaikh KAA, Ali OHA and Mohamed YA (2013). Seed borne fungal pathogens associated with common bean (Phaseolus vulgaris L.) seeds and their impact on germination. Journal of Environmental Studies, 11(03): 19-26.

[17] Haikal NZ (2008).Effect of the filtrate of pathogenic fungi of Soyabean on seed germination and seedling parameters. J. Appl. Sci. Res., 4: 48-52.

[18] Campbell SJ and Landis TD (1990).Managing seedborne diseases in western forest nurseries. Tree planters' Notes, 41(4): 3-7.

[19] Persson L, Bodker L and Larsson WM (1997). Prevalence and pathogenicity of foot and root rot in Southern Scandinavia. Plant Disease, 81: 171-174.
[20] Sheela S (2015).Isolation of Seed Borne Fungi Associated with Pigeon pea (Cajanuscajan, Linn.) Seeds. IJSR,5 (7): 45-49.

[21] Avinash TS and Ravishankar RV (2013). Identification of diverse fungi related with selected cucurbitaceae vegetables. Journal of Agricultural Technology, 9(7): 1837-1848.

[22] Wilman K, Stepien L, Fabianska I and Kachlicki $\mathbf{P}$ (2014). Plantpathogenic fungi in seeds of different pea cultivars in Poland. A rchives of Industrial Hygiene and Toxicology, 65 (3): 329-338.

[23] Ozgonen $\mathbf{H}$ and Gulcu M (2011). Determination of mycoflora of pea (Pisumsativum) seeds and the effects of Rhizobium leguminosorumon fungal pathogens of peas. African Journal of Biotechnology, 10 (33): 6235-6240.

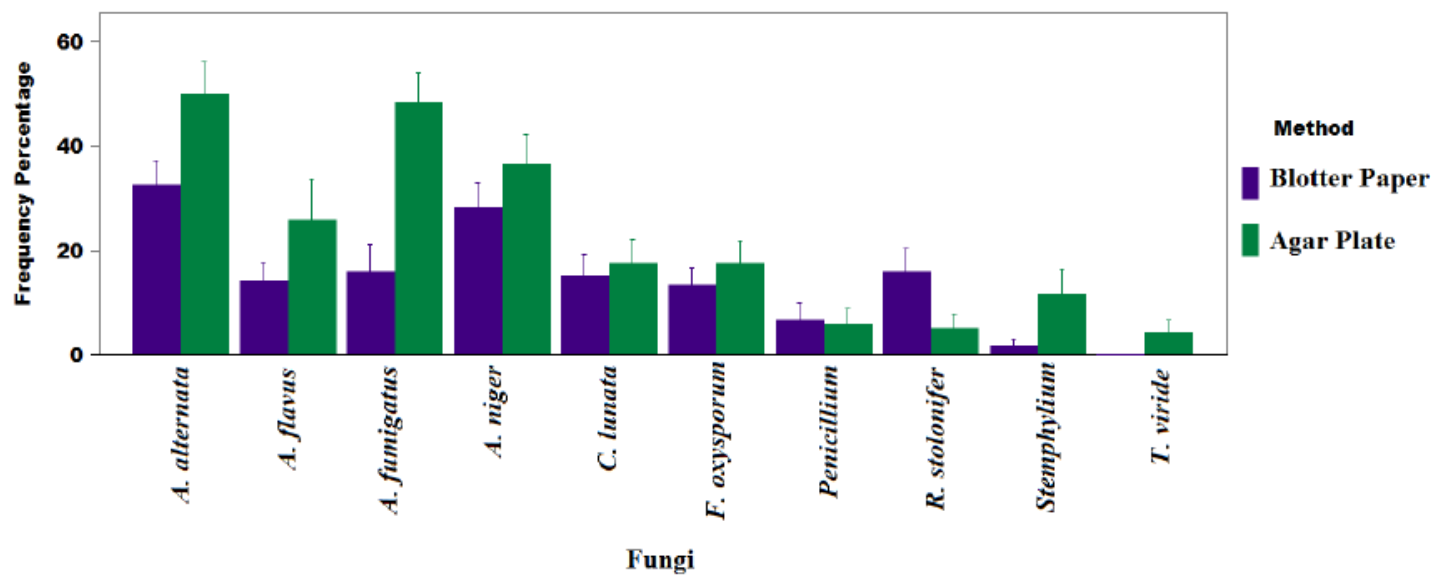

Fig 1. Comparison of blotter paper and agar plate methods for frequency percent of seed associated fungi isolated from the peas seed sample of 2016 and 2017.

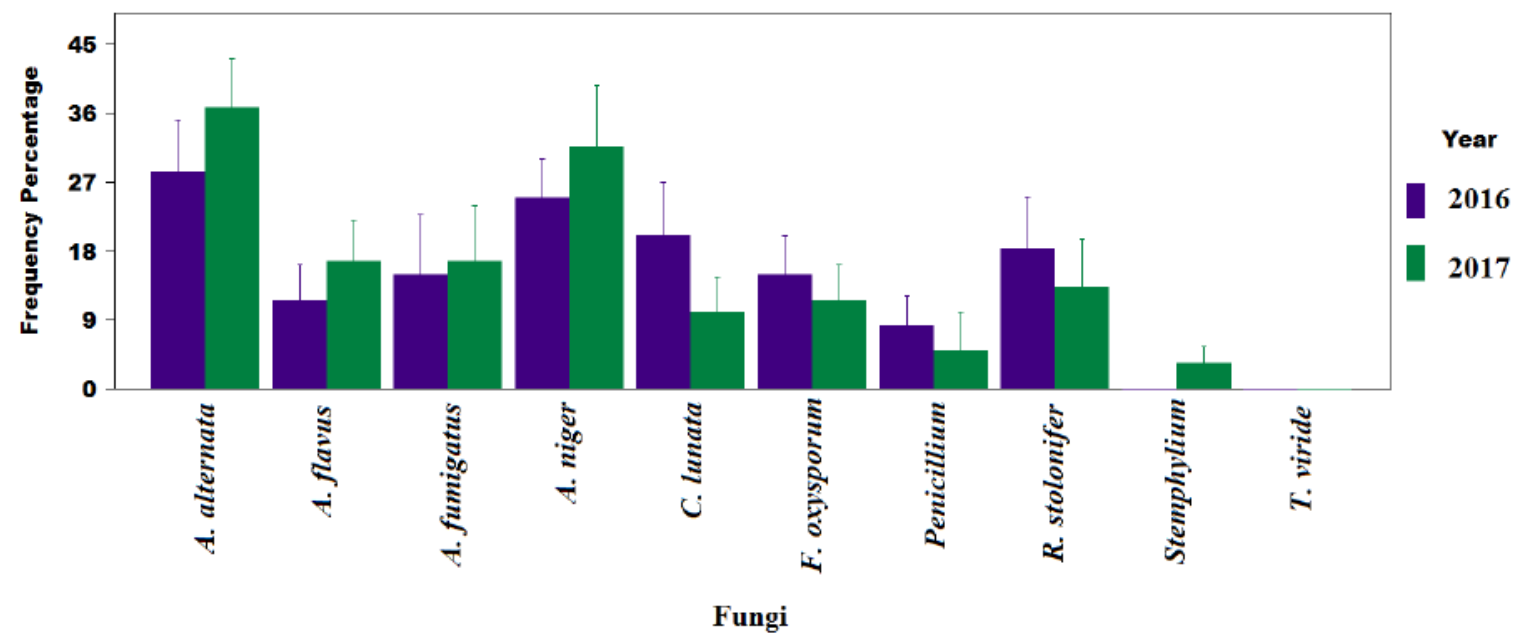

Fig 2. Frequency percent of seed associated fungi isolated through the blotter paper method from the peas seeds sample of 2016 and 2017. 


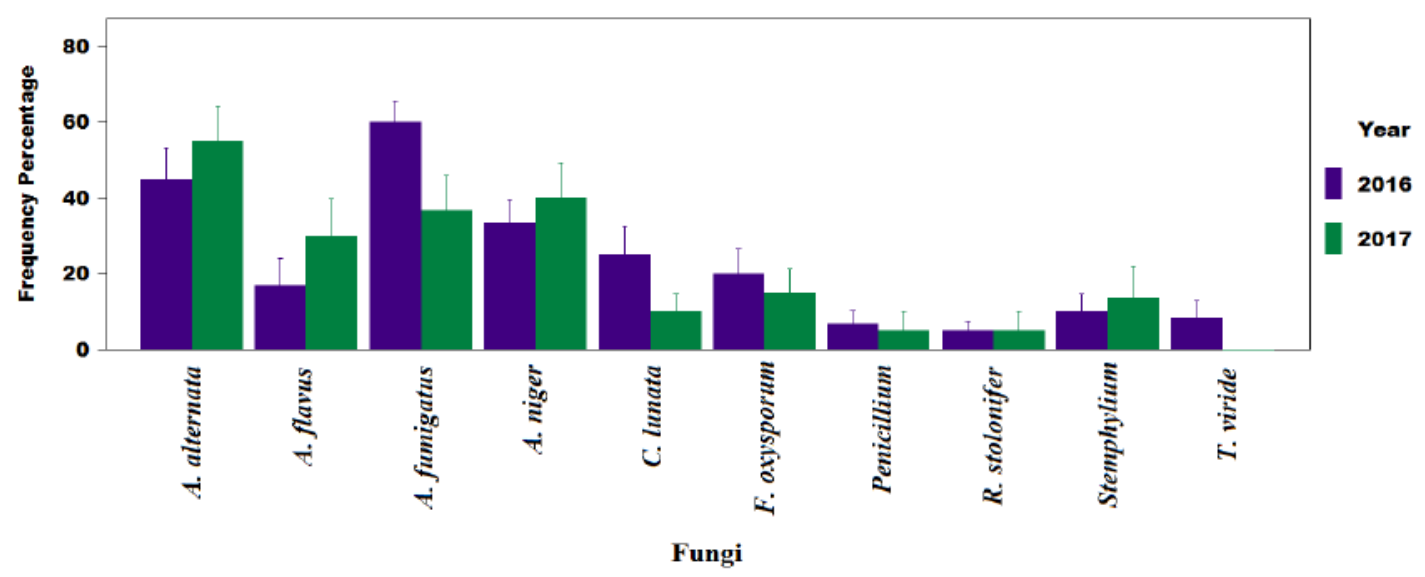

Fig 3. Frequency percent of seed associated fungi isolated through the agar plate method from the peas seed samples of 2016 and 2017.

Table 1. Analysis of variance for combine frequency percent offungi isolated through blotter paper and agar plate methods from pea vegetable seeds

\begin{tabular}{|l|c|c|c|c|c|c|}
\hline Source & DF & SS & MS & F & P & Remarks \\
\hline Fungi & 9 & 73891 & 8210.09 & 17.36 & 0.0000 & $* *$ \\
\hline Year & 1 & 41 & 40.83 & 0.09 & 0.7690 & - \\
\hline Plate & 11 & 2309 & 209.92 & 0.44 & 0.9357 & - \\
\hline Method & 1 & 7521 & 7520.83 & 15.9 & 0.0001 & - \\
\hline Fungi*Year & 9 & 7118 & 790.83 & 1.67 & 0.0935 & - \\
\hline Fungi*Method & 9 & 14404 & 1600.46 & 3.38 & 0.0005 & - \\
\hline Fungi*Year*Method & 10 & 2792 & 279.17 & 0.59 & 0.8223 & - \\
\hline Error & 429 & 202924 & 473.02 & - & - & - \\
\hline Total & 479 & 310999 & - & - & - & - \\
\hline CV & 118.9 & - & - & - & - & - \\
\hline
\end{tabular}

\section{** Highly Significant}

Table 2.The extent of seed associated mycoflora isolated through blotter paper and agar plates methods from peas seeds.

\begin{tabular}{|c|c|c|c|c|}
\hline \multirow{2}{*}{ Fungi } & \multicolumn{4}{|c|}{ Overall Frequency Percent* } \\
\hline & \multicolumn{2}{|l|}{ Blotter Paper Method } & \multicolumn{2}{|c|}{ Agar Plate Method } \\
\hline A. alternata & 32.5 & $\mathrm{a}$ & 50.00 & $\mathrm{a}$ \\
\hline A. niger & 28.33 & $\mathrm{a}$ & 36.67 & $\mathrm{~b}$ \\
\hline A. fumigates & 15.83 & $\mathrm{~b}$ & 48.33 & $\mathrm{ab}$ \\
\hline$R$. stolonifer & 15.83 & $\mathrm{~b}$ & 5.00 & de \\
\hline C. lunata & 15.00 & $\mathrm{~b}$ & 17.50 & $\mathrm{~cd}$ \\
\hline A. flavus & 14.17 & $\mathrm{~b}$ & 23.33 & $\mathrm{c}$ \\
\hline F. oxysporum & 13.33 & $\mathrm{~b}$ & 17.50 & $\mathrm{~cd}$ \\
\hline Penicilliumsp. & 6.67 & $\mathrm{bc}$ & 5.83 & de \\
\hline Stemphyliumsp. & 1.67 & $\mathrm{c}$ & 11.67 & cde \\
\hline T. viride & - & & 4.17 & $\mathrm{e}$ \\
\hline $\mathrm{SE}$ & 5.4743 & & 6.7562 & \\
\hline LSD $P<0.05$ & 10.792 & & 13.319 & \\
\hline
\end{tabular}

Note: Figures following the similar letter with in a colu mn are not significantly varied accord ing to the LSD (least significant difference) test at $P<0.05$.

*Overall mean frequency percent of two years 2016 and 2017 seeds samples. 